Original Article

\title{
What are patients with Rett syndrome interested in?
}

\author{
Daisuke Hirano, OTR, PhD $\left.{ }^{1,2}\right)^{*}$, TAKamichi TANiguchi, OTR, PhD ${ }^{1,3)}$
}

1) Graduate School of Health and Welfare Sciences, International University of Health and Welfare: 2600-1 Kitakanemaru, Ohtawara, Tochigi 324-8501, Japan

2) Department of Occupational Therapy, School of Health Sciences at Narita, International University of Health and Welfare, Japan

3) Department of Occupational Therapy, School of Health Sciences at Ohtawara, International University of Health and Welfare, Japan

\begin{abstract}
Purpose] Rett syndrome is a severe neurodevelopmental disease; individuals typically have no verbal skills or purposeful hand movements. In clinical settings, knowledge of their interests would be helpful for therapy. Therefore, we investigated the interests of Rett syndrome patients. [Subjects and Methods] In 2016, we sent a questionnaire regarding the interests of individuals with Rett syndrome to 1,016 directors of schools for special needs education and 204 directors of rehabilitation departments (130 facilities for persons with severe motor and intellectual disabilities, 73 wards for patients with severe motor and intellectual disabilities, and the National Hospital Organization and National Center Hospital, and the National Center of Neurology and Psychiatry) in Japan. We used descriptive statistics and content analysis to examine the answers to the questionnaires. [Results] Information was acquired from 216 individuals (3-53 years old) with Rett syndrome. 92.9\% of the individuals were reported to have some interests (e.g., in people, music, things to see, animation, or books). [Conclusion] Individuals with Rett syndrome were observed to be interested in various things despite their having severe motor and intellectual disabilities. These findings suggest that family members and care staff might facilitate various changes or developments of these individuals and discover their hidden strengths by focusing on their interests.

Key words: Rett syndrome, Severe motor and intellectual disabilities
\end{abstract}

(This article was submitted Sep. 29, 2017, and was accepted Nov. 15, 2017)

\section{INTRODUCTION}

Rett syndrome was described originally in German in the Austrian medical literature in 1966 by Andreas Rett ${ }^{1)}$. It is a severe neurodevelopmental disease affecting approximately 1 in 10,000 live female births and is often caused by mutations in the gene encoding methyl-CpG binding protein $2(\mathrm{MECP} 2)^{2)}$. Individuals with Rett syndrome exhibit partial or complete loss of acquired purposeful hand skills; partial or complete loss of acquired spoken language; impaired (dyspraxic) or absence of gait; and stereotypic hand movements such as hand wringing/squeezing, clapping/tapping, mouthing, and washing/rubbing automatisms ${ }^{2}$.

Intense eye communication, "eye pointing," is a supportive criterion for atypical Rett syndrome ${ }^{2)}$. Eye-tracker has been used to evaluate eye gaze in individuals with Rett syndrome ${ }^{3)}$. Individuals with Rett syndrome are known to have musical preferences ${ }^{4-8)}$. But, despite the clinical indications that they show interests in some items, such interests have not been carefully studied in a cross-sectional manner. Thus, we investigated the interests of individuals with Rett syndrome.

*Corresponding author. Daisuke Hirano (E-mail: dhirano@iuhw.ac.jp)

(C2018 The Society of Physical Therapy Science. Published by IPEC Inc.

(c) (1) $\odot$ This is an open-access article distributed under the terms of the Creative Commons Attribution Non-Commercial No Deriva-

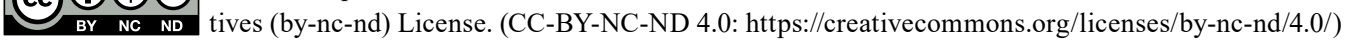




\section{SUBJECTS AND METHODS}

In 2016, a questionnaire was sent to 1,016 directors of schools for special needs education and 204 directors of departments of rehabilitation (consisting of 130 facilities for persons with severe motor and intellectual disabilities [SMID], 73 wards for patients with SMID, and the National Hospital Organization and National Center Hospital, National Center of Neurology and Psychiatry) in Japan. We sent up to 5 questionnaires per institution, for a maximum of 5 individuals with Rett syndrome. This study was approved by the institutional ethics committee of the International University of Health and Welfare (approval No. 16-Io-30).

The questionnaire consisted of 17 headings (age, grade of severity, period during which the answerer made their observations, related profession, purposeful hand movements, types of stereotypical hand movements, increased stereotypical hand movements, decreased stereotypical hand movements, interventions that reduced stereotypic hand movements, handedness, skin injuries, joint contracture, use of upper extremity splints, visual function, ophthalmic findings, use of visual function in rehabilitation or education, and interests), tailored by the authors for individuals with Rett syndrome. Answers to questions concerning age, grade of severity (Yokochi classification ${ }^{9)}$ ) and interests were analyzed in this study. Multiple answers were allowed and "interests" were based on free descriptions, not chosen from a list of possible answers. Answers were provided by the teachers, physical therapists, or occupational therapists based on their observations. Descriptive statistics and content analysis were used to examine the frequency of answers in each question. Averages or ranges were calculated for ages and grades of severity in descriptive statistics. During the content analysis, two authors grouped similar answers into categories and subcategories from the results of free descriptions of interests.

\section{RESULTS}

Information from 216 individuals (from 82 schools for special needs education and 43 facilities for persons with SMID) with Rett syndrome (based on institutional diagnoses) was collected in this study. The mean age of the subjects was $18.9 \pm$ 11.1 years and median age was 15.5 (3.7-53.4) years (under 10 years: 28 cases; $10-19: 109 ; 20-29: 17 ; 30-39$ : 19; 40-49: 9; 50-59: 4). Disease severity was determined using the Yokochi classification ${ }^{9)}$, taking into account ratings of severity of both motor and intellectual functions (Table 1). Age was unknown in 30 cases, and the Yokochi classification ${ }^{9)}$ score was unknown in 17 individuals. These cases were still included in the results compiling the presence and absence of various interests. The presence or absence of interests was unknown in 6 cases, but these cases were still included in the data shown in Table 1. Therefore, the presence and absence of various interests of 210 patients were analyzed.

Of these 210 subjects, $195(92.9 \%)$ of them expressed interest in various items (Table 2). The most frequently listed interests included people, music, things to see, animations, or books. The maximum number of concrete names of interests observed in an individual subject was 7 , the minimum was 0 , the average $2.3 \pm 1.5$, and the median was 2 .

\section{DISCUSSION}

To our knowledge, this is the first investigation of the interests of individuals with Rett syndrome. Most of the individuals were reported to have interests in some items, despite being mostly classified as A1-B6 in the Yokochi classification ${ }^{9)}$. Because these severities indicate that intellectual development was limited to the abilities to understand simple words or no understanding of words, their severities were not mild and are considered to be SMID. Our findings suggest that we can

Table 1. Disease severity of individuals with Rett syndrome ${ }^{9)}(\mathrm{N}=199)$

\begin{tabular}{lcccccc}
\hline Intellectual development & \multicolumn{7}{c}{ Locomotion } \\
& $\begin{array}{c}\text { Walk } \\
\text { outdoors }\end{array}$ & $\begin{array}{c}\text { Walk } \\
\text { indoors }\end{array}$ & $\begin{array}{c}\text { Locomote } \\
\text { indoors }\end{array}$ & Sit & $\begin{array}{c}\text { Roll } \\
\text { over }\end{array}$ & $\begin{array}{c}\text { No } \\
\text { rolling }\end{array}$ \\
\hline Do basic arithmetic & E6* & E5 & E4 & E3 & E2 & E1 \\
& $1^{\S}$ & 0 & 0 & 0 & 0 & 0 \\
Read simple letters and figures & D6 & D5 & D4 & D3 & D2 & D1 \\
Understand simple colors and & 1 & 0 & 0 & 0 & 0 & 0 \\
numbers & $\mathrm{C} 6$ & $\mathrm{C} 5$ & $\mathrm{C} 4$ & $\mathrm{C} 3$ & $\mathrm{C} 2$ & $\mathrm{C} 1$ \\
Understand simple words & 1 & 0 & 0 & 0 & 0 & 0 \\
& $\mathrm{~B} 6$ & $\mathrm{~B} 5$ & $\mathrm{~B} 4$ & $\mathrm{~B} 3$ & $\mathrm{~B} 2$ & $\mathrm{~B} 1$ \\
No understanding of words & 37 & 7 & 5 & 12 & 5 & 11 \\
& $\mathrm{~A} 6$ & $\mathrm{~A} 5$ & $\mathrm{~A} 4$ & $\mathrm{~A} 3$ & $\mathrm{~A} 2$ & $\mathrm{~A} 1$ \\
\end{tabular}

*(A1-E6): Yokochi classification severity class; ${ }^{\S}$ Number of cases. 
possibly facilitate various changes in or development of subjects with Rett syndrome and discover their hidden strengths by focusing on their interests.

Individuals with Rett syndrome were reported to have musical preferences ${ }^{4-8)}$ or to exhibit eye pointing ${ }^{3)}$. In this study, most of the subjects were observed to be interested in various items, such as people, music, things to see, animations, or books. If family members or care staff cannot discover the interests of individuals with Rett syndrome, perhaps these results will be of help in the clinical setting to discern such interests. This study may be useful to examine habilitation plans for individuals with Rett syndrome.

These results might be biased by the persons providing answers to the questionnaire, as they were not given by the patients themselves, but rather were based on the answerers' observations. We also did not acquire any information on detailed diagnosis, regression age, or status of MECP2 or other mutations, all of which affect the functioning of individuals with Rett

Table 2. Interests of Rett syndrome individuals ( $\mathrm{N}=195)$

\begin{tabular}{|c|c|c|c|c|c|c|c|}
\hline Category & $\mathrm{N}$ & Subcategory & $\mathrm{N}$ & Category & $\mathrm{N}$ & Subcategory & $\mathrm{N}$ \\
\hline \multirow[t]{13}{*}{ People } & \multirow[t]{13}{*}{82} & People & 16 & Things to hear & 29 & Musical instrument & 17 \\
\hline & & Friend & 15 & & & Sounded object & 12 \\
\hline & & Relatives & 14 & Food/meal & 27 & Food/meal & 27 \\
\hline & & Teacher/staff & 8 & Vestibular stimulus & 15 & Vestibular stimulus & 15 \\
\hline & & People's face/expression & 7 & Operation & 12 & Switch & 4 \\
\hline & & People's movement & 6 & & & Making & 3 \\
\hline & & Specific people & 4 & & & Hold & 3 \\
\hline & & Familiar people & 3 & & & DVD operation and choice & 2 \\
\hline & & Surrounding people & 3 & $\mathrm{iPad} /$ Smartphone & 10 & iPad & 9 \\
\hline & & Adult & 2 & & & Smartphone & 1 \\
\hline & & Family & 2 & Walk & 6 & Walk & 2 \\
\hline & & Child & 1 & & & Stroll & 2 \\
\hline & & Oneself in mirror & 1 & & & Walker & 2 \\
\hline \multirow[t]{3}{*}{ Music } & \multirow[t]{3}{*}{64} & Music & 43 & Animal & 5 & Animal & 5 \\
\hline & & Song & 18 & Vinyl & 3 & Vinyl & 3 \\
\hline & & $\mathrm{CD}$ & 3 & Plushie & 3 & Plushie & 3 \\
\hline \multirow[t]{11}{*}{ Things to see } & \multirow[t]{11}{*}{63} & Lighted object & 25 & Ball & 3 & Ball & 3 \\
\hline & & Sparkling object & 8 & Textured object & 3 & Textured object & 3 \\
\hline & & Moving object & 8 & Lighted and sounded object & 3 & Lighted and sounded object & 3 \\
\hline & & Beautiful object & 5 & Outdoors & 3 & Outdoors & 3 \\
\hline & & Pattern/design & 4 & Teaching materials & 2 & Teaching materials & 2 \\
\hline & & Colorful object & 3 & Toy & 2 & Toy & 2 \\
\hline & & Photo & 3 & Musical movie & 2 & Musical movie & 2 \\
\hline & & Picture & 3 & Doll & 2 & Doll & 2 \\
\hline & & Visual stimulus & 2 & Others & 14 & Object & 1 \\
\hline & & Specific color & 1 & & & Basket & 1 \\
\hline & & Mirror & 1 & & & Tissue box & 1 \\
\hline \multirow[t]{8}{*}{ Animation } & \multirow[t]{8}{*}{59} & $\mathrm{TV}$ & 12 & & & Cup & 1 \\
\hline & & Video & 7 & & & Paper & 1 \\
\hline & & DVD & 7 & & & Key chain & 1 \\
\hline & & Children's TV show & 11 & & & Clock & 1 \\
\hline & & Animation & 5 & & & Towel & 1 \\
\hline & & Musical video & 1 & & & Vehicle & 1 \\
\hline & & Character & 12 & & & Playing house & 1 \\
\hline & & Idol & 4 & & & Game & 1 \\
\hline \multirow[t]{4}{*}{ Book } & \multirow[t]{4}{*}{45} & Picture book & 26 & & & Ironing & 1 \\
\hline & & Musical picture book & 13 & & & Flavor & 1 \\
\hline & & Book & 3 & & & Vibration & 1 \\
\hline & & Magazine & 3 & & & & \\
\hline
\end{tabular}

Multiple answers allowed. 
syndrome. In the future, the use of a database, comprising a population-based register of confirmed cases of Rett syndrome, with data collected from questionnaires sent to families, teachers, and medical staff such as clinicians or rehabilitation staff, will be useful for conducting a multilateral analysis.

\section{Funding}

The present study was supported by JSPS KAKENHI Grant Number JP16K17472.

\section{ACKNOWLEDGEMENT}

We thank all participants who answered the questionnaire in this study, which has provided us with invaluable information.

\section{REFERENCES}

1) Rett A: [On a unusual brain atrophy syndrome in hyperammonemia in childhood]. Wien Med Wochenschr, 1966, 116: 723-726 (In German). [Medline]

2) Neul JL, Kaufmann WE, Glaze DG, et al. RettSearch Consortium: Rett syndrome: revised diagnostic criteria and nomenclature. Ann Neurol, 2010, 68: 944-950. [Medline] [CrossRef]

3) Hirano D, Taniguchi T: Application of eye-tracker to individuals with Rett syndrome: a systematic review. Int J Phys Med Rehabil, $2015,3: 292$.

4) Kerr AM, Archer HL, Evans JC, et al.: People with MECP2 mutation-positive Rett disorder who converse. J Intellect Disabil Res, 2006, 50: 386-394. [Medline] [CrossRef]

5) Merker B, Bergström-Isacsson M, Witt Engerström I: Music and the Rett disorder: the Swedish Rett centre survey. Nord J Music Ther, 2001, 10: 42-53. [CrossRef]

6) Yasuhara A, Sugiyama Y: Music therapy for children with Rett syndrome. Brain Dev, 2001, 23: S82-S84. [Medline] [CrossRef]

7) Wesecky A: Music therapy for children with Rett syndrome. Am J Med Genet Suppl, 1986, 1: 253-257. [Medline] [CrossRef]

8) Wigram T, Lawrence M: Music therapy as a tool for assessing hand use and communicativeness in children with Rett Syndrome. Brain Dev, 2005, 27: S95-S96. [Medline] [CrossRef]

9) Morimoto M, Suzaki I, Satomura S, et al.: Epilepsy properties and seizure suppression in a severe motor and intellectual disabilities. Int J Clin Med, 2016, 7: 182-192. [CrossRef] 